\title{
¿GOBERNANZA Y NUEVA GESTIÓN PÚBLICA PARA LA PAZ? \\ NOTAS SOBRE EL PROCESO DE IMPLEMENTACIÓN DEL ACUERDO FINAL EN COLOMBIA ${ }^{1}$
}

\author{
José Francisco Puello-Socarrás ${ }^{2}$
}

http://dx.doi.org/10.1590/1413-2311.208.83540

\section{RESUMEN}

El artículo reflexiona sobre dos dimensiones (relativamente) desatendidas dentro de los análisis actuales sobre el proceso de la implementación del Acuerdo Final de Paz en Colombia: la gobernanza y la nueva gestión pública. Interroga los inconvenientes de prorrogar los ajustes y reformas institucionales acordadas entre el Gobierno colombiano y la antigua guerrilla de las FARC-EP (hoy, el partido político: la Fuerza Alternativa Revolucionaria del Común, FARC), en los niveles gubernativo y organizacional estatales, problematizando las situaciones y las condiciones requeridas para lograr el propósito dentro de la etapa de transición en el país, desde los escenarios de la guerra hacia los de la Paz y su construcción estable y duradera. Previene sobre la virtual 'disonancia cognitiva' del status quo como la impronta del régimen socioeconómico y sistema político colombianos, y la inconveniencia de mantener los formatos pro-neoliberales que obstaculizan la apertura hacia procesos de socialización y democratización en Colombia para el período pos-acuerdo.

Palabras-clave: Construcción de paz. Pos-acuerdo en Colombia. Gobernanza. Nueva Gestión Pública. Neoliberalismo.

\footnotetext{
${ }^{1}$ Recebido em 03/06/208, aceito em 31/07/2018.

${ }^{2}$ Escuela Superior de Administración Pública (Bogotá, Colombia) - josepuel@esap.edu.co
} 


\title{
GOVERNANÇA E NOVA ADMINISTRAÇÃO PÚbLICA PARA A PAZ? NOTAS SOBRE O PROCESSO DE IMPLEMENTAÇÃO DO ACORDO FINAL EM COLÔMBIA
}

\begin{abstract}
RESUMO
O artigo reflete sobre duas dimensões (relativamente) desconsideradas nas análises atuais sobre o processo de implementação do Acordo Final de Paz na Colômbia: governança e nova administração pública. Interroga as inconveniências de prorrogar os ajustes e reformas institucionais acordadas entre o Governo colombiano e a antiga guerrilha das FARC-EP (hoje, o partido político Fuerza Alternativa Revolucionaria del Común, FARC), nos níveis governativos e organizacional estatais, problematizando as situações e as condições requeridas para atingir o propósito na etapa de transição no país, desde os cenários da guerra até os de Paz, e sua construção estável e duradoura. Alerta sobre a virtual 'dissonância cognitiva' do status quo como característica do regime socioeconômico e sistema político colombianos, e a inconveniência de manter os formatos pós-neoliberais que obstaculizam a abertura a processos de socialização e democratização na Colômbia no período pós-acordo.
\end{abstract}

Palavras-chave: Construção da paz. Pós-acordo na Colômbia. Governança. Nova Administração Pública.Neoliberalismo.

\section{GOVERNANCE AND NEW PUBLIC MANAGEMENT FOR PEACE? NOTES ON THE IMPLEMENTATION OF THE FINAL AGRREMENT IN COLOMBIA}

\begin{abstract}
The article reflects on two dimensions (relatively) unconsidered in the contemporary analysis of the implementation process od the Final Peace Agreement in Colombia: governance and new public management. It interrogates the inconveniences of postponing the agreed institutional reforms and adjustments agreed between the Colombian Government and the former guerrilla of the FARC-EP (today the political party: Fuerza Alternativa Revolucionaria del Común - FARC), at the governmental and organizational levels of the state, discussing the situations and conditions required to achieve the purposes at the transitional moment in the country, from the scenario of war to a scenario of Peace and its
\end{abstract}


stable and longstanding construction. It calls attention for the virtual 'cognitive dissonance' of the status quo as a characteristic of the Colombian socioeconomic regimen and political system which are obstacles for processes of socialization and democratization in the postagreement period.

Keywords: Peace construction. Colombia post-agreement. Governance. New Public Management. Neoliberalism.

Locura es hacer las mismas cosas una y otra vez, esperando un resultado distinto. Rita Mae Brown (1983) - Sudden Death

\section{BREVE SÍNTESIS SOBRE EL (NUEVO) ACUERDO FINAL PARA LA PAZ}

Entre los meses de febrero y agosto del año 2012, el Gobierno colombiano y las Fuerzas Armadas Revolucionarias de Colombia - Ejército del Pueblo (FARC-EP) sostuvieron los llamados: Encuentros exploratorios con el propósito de "poner fin al conflicto armado nacional" (MESA DE CONVERSACIONES, 2017a, p. 1). Para ese momento, el último ciclo de guerras internas en Colombia se había prolongado ininterrumpidamente por más de medio siglo. En este caso, al menos desde 1966, fecha en la cual se registra la "Declaración política de la II Conferencia del Bloque Guerrillero del Sur", el documento constitutivo y fundacional de las FARC-EP (VILLAMIZAR, 2017, p. 777-779).

A partir de los diálogos exploratorios y en adelante, el 'Acuerdo General para la terminación del Conflicto y la Construcción de una Paz estable y duradera' marcaría la agenda de las conversaciones entre las partes y que fueron desarrolladas en La Habana (Cuba), Luego de cuatro años (agosto de 2016), el Gobierno nacional y las FARC-EP suscribieron finalmente el 'Acuerdo Final para la terminación del Conflicto y la Construcción de una Paz estable y duradera'. El documento definitivo, no obstante, debió ser sometido ante una consulta popular para la aprobación -o la desaprobación- a través de un plebiscito ${ }^{3}$, en

\footnotetext{
3 Según la Constitución política hoy vigente en Colombia, el Plebiscito es uno de los mecanismos de participación popular que es convocado por el Presidente de la República y mediante el cual se formula una pregunta (genérica) ante el electorado, con el fin que avale (o no) una decisión tomada por el Ejecutivo.
} 
virtud del mandato jurisprudencial de la Corte Constitucional, instancia judicial encargada de velar por la integridad, supremacía y cumplimiento de la Carta Política vigente desde el año 1991 y que consagra: "La paz es un derecho y un deber de obligatorio cumplimiento" (artículo 22) para el Estado y los ciudadanos colombianos. El resultado electoral de la consulta, realizada el 2 de octubre de 2016 obtuvo los resultados presentados en la Tabla 1.

Tabla 1 - Resultados Plebiscito para refrendar electoralmente el Acuerdo final de Paz en Colombia (octubre 2016), ante la pregunta: ¿Apoya el acuerdo final para la terminación del conflicto y construcción de una paz estable y duradera?

\begin{tabular}{l|l|l}
\hline Elección & Total de votos & Porcentaje \\
\hline Sí & 6.377 .464 & $49,79 \%$ \\
\hline No & 6.431 .372 & $50,21 \%$ \\
\hline Votos nulos & 170.946 & \multirow{2}{*}{$1,97 \%$} \\
\hline Votos sin marcar & 86.243 & \multirow{2}{*}{ Porcentaje } \\
\hline Registro electoral (2016) & Total de votantes & $37,44 \%$ \\
\hline Participación total & 13.066 .025 & $100 \%$ \\
\hline Votantes habilitados & 34.899 .945 & $62,56 \%$ \\
\cline { 1 - 2 } Abstención electoral & 21.833 .920 &
\end{tabular}

Fuente: elaborado por el autor con base en página virtual de la Registraduría Nacional del Estado Civil (2018).

Ante el triunfo mayoritario del "NO" en la consulta - aunque por un margen exiguo y registrando un alto índice de abstención electoral - una de las opciones que fueron previstas por la Corte Constitucional fue garantizar la competencia del Presidente de la República (en cabeza de Juan Manuel Santos) para continuar con el proceso de paz. Por ello,

Luego del plebiscito... el Gobierno Nacional sostuvo una serie de intensas reuniones con representantes del $\mathrm{NO}$, para oír sus observaciones y preocupaciones sobre el Acuerdo Final (...) Como consecuencia de esas reuniones, las delegaciones del Gobierno y las FARC acordaron una serie de importantes y numerosos cambios, ajustes y precisiones al texto del Acuerdo, y en consecuencia firmaron un nuevo Acuerdo (MESA DE CONVERSACIONES, 2017b, p. 3).

Cumplidos estos protocolos, el nuevo documento fue ratificado entre las partes y elevado como Acuerdo Especial para efectos de las obligaciones internacionales del Estado 
colombiano respecto al Derecho Internacional Humanitario, aunque sin introducirlo al ordenamiento jurídico (MESA DE CONVERSACIONES, 2017b, p. 22).

\section{LA TRANSICIÓN HACIA UNA PAZ ESTABLE Y DURADERA: DEL DISEÑO A LA IMPLEMENTACIÓN DEL ACUERDO FINAL}

El contenido del Acuerdo de Paz abría la posibilidad para construir un nuevo capítulo en la historia del país. El texto final y definitivo, a pesar de no significar cambios radicales es decir, de raíz- que modificaran las estructuras del régimen socio-económico y el sistema político colombianos, caracterizados históricamente por la impronta autoritaria y las profundas desigualdades de todo tipo (ingresos, género, étnica, territorial, propiedad de la tierras, etc.) (ver CHCV, 2015; PUELLO-SOCARRÁS; PUELLO-SOCARRÁS, 2017), sí suponía desatar un potencial transformador; puntualmente:

[...] una fase de transición [que contribuyera] a una mayor integración de nuestros territorios, una mayor inclusión social -en especial de quienes han vivido al margen del desarrollo y han padecido el conflicto- y a fortalecer nuestra democracia para que se despliegue en todo el territorio nacional y asegure que los conflictos sociales se transmiten por las vías institucionales, con plenas garantías para quienes participen en política (MESA DE CONVERSACIONES, 2017a, p. 6).

Entendiendo este horizonte político, el diseño del Acuerdo contemplaba seis "puntos" fundamentales, los cuales incluían aspectos tales como: (1) la Reforma Rural Integral; (2) la Participación política y la Apertura democrática; (3) el Fin del conflicto (armado); (4) la Solución al problema de las drogas ilícitas; (5) un Acuerdo sobre las Víctimas del Conflicto, incluido un Sistema Integral de Verdad, Justicia, Reparación y No Repetición; la Jurisdicción Especial para la Paz y compromisos sobre Derechos Humanos; y, (6) los principios generales para la Implementación del Acuerdo Final en el que preveían los mecanismos y criterios para su monitoreo y verificación. Complementario a los "puntos", el Acuerdo final se estructuraba en forma sistémica e integral, a partir de los enfoques transversales (género, étnico, territorial).

El proceso de transición y puesta en marcha de las acciones acordadas precisaba entonces, al menos, dos cuestiones claves relativas al proceso de implementación. 
Por un lado, a través de diferentes tipos de producción legislativa (v.gr. reformas constitucionales, leyes, normatividad procedimental, entre otras), propiciar las situaciones en la institucionalidad estatal para iniciar la fase de implementación temprana la cual, en el corto plazo, permitiera avanzar rápidamente en la consecución de las acciones prioritarias del Acuerdo final (especialmente, los Programas de Desarrollo con Enfoque Territorial). Estos ajustes institucionales permitirían seguir desatando, ahora en el mediano y largo plazos, la fase de implementación tardía, asegurando el cumplimiento de los objetivos consignados en el Acuerdo.

Por otro lado, la segunda cuestión crucial de la implementación (tardía) precisaría la traducción de los aspectos del Acuerdo, en clave de la producción de políticas/medidas públicas. En este último aspecto, resultaba preciso atender -en primer lugar- la dimensión específica de las reformas organizacionales, al nivel de la institucionalidad estatal. El principal instrumento para lograr este propósito proponía al Plan Marco de Implementación (PMI) como la bitácora de las políticas públicas en Colombia. El PMI sería parte de un Capítulo especial para la Paz, en cada uno de los Planes de Desarrollo de los gobiernos venideros (cuatrienales) y, en esa forma, materializar los propósitos del Acuerdo durante los diez años consecutivos a la implementación prioritaria, tal y como se había pactado - ver Punto 6: "Implementación, verificación y refrendación" (MESA DE CONVERSACIONES, 2017a, p. 193-205).

Aunque sin acotaciones expresas en el texto, en segundo lugar, el sentido común dictaba que los ajustes y las reformas tenían que dirigirse también -paralela y simultáneamente- hacia los cambios necesarios al nivel de las formas y relaciones gubernamentales; de lo contrario, las imposibilidades de implementar integralmente un proceso de paz exitoso podían aumentar paulatinamente. Esta dimensión permanece hoy por hoy desatendida en los análisis sobre la implementación e igualmente en la planeación planificada de la construcción de la Paz que rige todo este proceso.

\section{AVATARES DEL PROCESO DE IMPLEMENTACIÓN: FASES TEMPRANA Y TARDÍA}

Después de dieciocho (18) meses de haberse iniciado formalmente la etapa temprana de la implementación, se esperarían avances sustanciales, y resultados e impactos concretos derivados del Acuerdo Final, en la perspectiva de una construcción de la paz estable y duradera. Sin embargo, conforme pasa el tiempo, los hechos muestran un panorama bien 
distinto, incluso, bastante sombrío. Paralelo a los avances del proceso de implementación, los cuales se muestran modestos y débiles - aunque, sobre todo: erráticos-, las indefiniciones se acumulan.

Al contrario de lo sugerido por varios informes que evalúan la implementación (KROC, 2017; ver PUELLO-SOCARRÁS, 2017) respecto al cumplimiento del Acuerdo, el caso colombiano viene consolidando una tendencia caracterizada por los retrasos, las dilaciones, el desconocimiento de lo acordado, las distorsiones y las simulaciones.

Contando con lo efectivamente alcanzado hasta este momento, se podría fácilmente asumir que asistimos a un proceso de pacificación centrado casi exclusivamente en uno de los actores del conflicto armado: las antiguas Fuerzas Armadas Revolucionarias de Colombia, Ejército del Pueblo (FARC-EP), hoy un partido político: la nueva Fuerza Alternativa Revolucionaria del Común (FARC), y no un proceso de Paz auténtico, convocado para superar las condiciones sociopolíticas y económicas estructurantes que propiciaron la persistencia del conflicto social y armado en Colombia durante más de medio siglo.

El futuro se carga entonces de incertidumbres a la hora de pronosticar los rumbos efectivos desde la coyuntura de las trayectorias y en perspectiva de las resoluciones estratégicas. Máxime cuando la fase de la implementación proyectada por el Acuerdo Final para las próximas décadas atraviesa por momentos críticos cruciales.

Entre los temas urgentes, el tipo de construcción de la Paz (peace-building) en el país, al parecer, se ha tornado secundario, desestimando varios asuntos claves. Los escenarios donde se han discutido aspectos fundamentales, tanto al nivel político como técnico, (v.gr. la definición del Plan Marco de la Implementación, PMI), sugieren que las modalidades de gobierno y organización institucionales previstas para hacer de la Paz una realidad social, seguirán limitándose a reproducir los viejos esquemas pro-neoliberales adoptados por el régimen político económico de la guerra, hoy plenamente vigentes: la gobernanza y la nueva gestión pública.

En vista que estas orientaciones aparecen con frecuencia como formulaciones poco familiares, reconstruimos una breve síntesis sobre su significado sociopolítico actual y su relación potencial y latente frente a las expectativas de consecución de una Paz estable y duradera.

\section{GOBERNANZA Y NUEVA GESTIÓN PÚBLICA EN PERSPECTIVA}


Dos de las principales transformaciones que se registran, a nivel global y con implicaciones regional y local, en las estructuras y el funcionamiento de los Estados-nación durante el último tercio del siglo $\mathrm{XX}$ tienen que ver con variaciones sustanciales en las formas gubernamentales y organizativas surgidas desde la década de $1970 \mathrm{~s}^{4}$.

Los cambios significaron el tránsito desde la Gobernabilidad y la Administración Pública -estructuras típicas del Estado Keynesiano de Bienestar (EKB, Welfare state) de la época de posguerra en los Estados Unidos y Europa- hacia nuevas estructuras globales: la Gobernanza y la (nueva) Gestión Pública, improntas paradigmáticas del Estado Schumpeteriano de Trabajo (EST, Workfare State) (ver JESSOP, 1999 y 2008) y su correlato punitivo (Prisonfare state) (ver WACQUANT, 2009); en su conjunto: el Estado Neoliberal comprensivo (PUELLO-SOCARRÁS, 2018) . $^{5}$

A diferencia de los países del capitalismo central, en América Latina y el Caribe, espacio donde nace y se reproduce inauguralmente el proyecto neoliberal que luego se globaliza, las transformaciones no se desencadenaron a partir de la crisis del EKB, experiencia inexistente en estas latitudes. En contraste, el Estado neoliberal latinoamericano evoluciona, primero, bajo el trasfondo del Estado Burocrático-Autoritario (EBA) (O’DONNELL, 1982), o también denominados Regímenes Tecnocrático-Militares (MARINI, $2008)^{6}$.

\footnotetext{
${ }^{4}$ Desde la década de 1970, la estrecha relación entre gobernanza y nueva gestión pública, y la construcción del Estado gerencial/empresarial, fueron anticipadas política e ideológicamente por el informe: The crisis of Democracy: Report on the Governability of Democracies of the Trilateral Commision (CROZIER; HUNTINGTON; WATANUKI, 1975). Más recientemente, el conjunto de las Instituciones Financieras Internacionales: el Fondo Monetario Internacional (FMI) y el Grupo del Banco Mundial (BM) han promocionado -condicionado e impuesto- ambos enfoques. Se destacan en ello, los roles jugados, a nivel global por la Organización para la Cooperación y el Desarrollo Económicos (OECD, por sus siglas en inglés), en su informe: Governance in transition. Public Management reforms in OECD countries (OECD, 1995) y local: Colombia: La implementación del buen gobierno (OECD, 2014); a nivel regional, por el Centro Latinoamericano de Administración para el Desarrollo (CLAD, 1998) en el "documento doctrinario", titulado: Una nueva gestión pública para América Latina. Para una síntesis teórica e histórica en torno a las nociones de gobernanza y nueva gestión pública, ver Serna de la Garza (2010).

${ }^{5}$ Nos referimos al Estado neoliberal comprensivo para subrayar que la nueva configuración del ETS debe entenderse bajo la fórmula: Workfare State + Prison State, cuestión que con frecuencia varios análisis omiten. El armazón del Estado Neoliberal tiene como referentes estructurantes el Trabajo y lo Punitivo, tal y como lo explica Wacquant $(2009$, p. 80 y 437) “(...) el reemplazo gradual de un (semi)Estado de bienestar por un Estado policial y penal para cual la criminalización de la marginalidad y el encarcelamiento punitivo de las categorías desfavorecidas funcionan a modo de política social en el nivel más bajo del orden étnico y de clase (...) el neoliberalismo produce no el recorte del gobierno sino la instalación de un Estado centauro liberal hacia arriba y paternalista hacia abajo que presenta caras radicalmente diferentes en los dos extremos de la jerarquía social: un rostro bello y atento hacia las clases media y alta, y un rostro temible y sombrío hacia la clase baja" [énfasis propio].

${ }^{6}$ Solís $(2016$, p. 122), anota, en relación con los procesos de legitimación del poder: “(...) los regímenes políticos de la periferia latinoamericana han sido en su mayoría, hasta los años noventa del siglo XX,
}

REAd | Porto Alegre - Vol. 24 - No 2 - Maio / Agosto 2018 - p. 31-49 
Posteriormente, en segundo lugar, esta forma estatal se extiende en locus e intensidades institucionalizando nuevas formas gubernamentales y esquemas postburocráticos y neo-gerenciales, los cuales mantienen y potencian los rezagos autoritarios heredados ${ }^{7}$, bajo nuevas modalidades y según la singularidad exhibida en casos específícos ${ }^{8}$. El componente punitivo del "lado de la oferta" del EST evidencia cómo la impronta autoritaria no sólo perdura, sino se renueva constantemente.

Como forma-estatal globalizada hoy realmente existente y actualmente vigente, sea desde la crisis del EKB en el capitalismo central o fruto de la sucesión del EBA en el capitalismo periférico, el ETS ha venido siendo respaldado y se encuentra doblemente condicionado por las dinámicas -las lógicas y, especialmente, las contradicciones- de la gobernanza (governance) como enfoque de gobierno político, y de la Nueva Gestión Pública (NGP o NPM, por sus siglas en inglés: new public management) como arquitectura organizativa estatal.

Por ello, le asiste toda la razón a Guerrero (2008) cuando captura lo esencial de estos acontecimientos, en comparación con los cambios experimentados por las burocracias estatales precedentes, cuando plantea: "Nueva gerencia pública: Neoliberalismo en Administración Pública" (véase también PUELLO-SOCARRÁS, 2008, p. 109-130;

dictaduras policíaco-militares" [énfasis propio]. Mientras que Rouquié (2011, p. 116) sintetiza para la década de 1960s, en adelante: “[...] La ambición de estos Estados terroristas es nada menos que restructurar la economía y la sociedad con el objeto de establecer un orden contrarrevolucionario permanente, así como una vida política y social sin riesgos para el statu quo". [énfasis propio]

${ }^{7}$ Varias aproximaciones que defienden y promueven los enfoques de gestión pública han llamado la atención sobre los presupuestos sociohistóricos y el "contexto de aplicación” en las sociedades latinoamericanas y sus configuraciones resultantes (ver RAMIÓ MATAS, 2001). Cabrero (1998, p. 31), por ejemplo, refiriéndose a las recomendaciones operativas desde la NGP y el diseño de estructuras organizacionales, subraya "(...) el argumento no tiene la misma repercusión en sociedades que surgieron históricamente de sistemas en los que la autoridad vertical es el elemento básico de referencia en cualquier acción organizada. La autoridad es el elemento de cohesión -al menos simbólicamente hablando- a través del cual se genera la cooperación" [énfasis propio]. Otra muestra del pensamiento convencional, a propósito de las reformas gestionarías a la administración pública en América Latina y el Caribe, declara: “(...) la mayoría de las administraciones de los países de la región siguen operando según un modelo patrimonial con baja autonomía y efectividad, donde apenas se destacan algunos países o algunos enclaves de racionalidad y eficacia" (ECHEBARRÍA; CORTÁZAR, 2007, p. 143); no obstante, estos enclaves intelectuales continúan insistiendo sobre la necesidad de profundizar estas reformas.

${ }^{8}$ Nos referimos a dos tendencias típicamente latinoamericanas y caribeñas consolidadas durante las últimas décadas del siglo XX: (1) los regímenes de las democracias delegativas (ver O’DONNELL, 1992), donde se supera formal aunque no sustancialmente, los gobiernos autoritarios instalados manu militari por las dictaduras cívico-militares (tempranamente Argentina, por ejemplo); y, (2) los regímenes anocráticos donde el gobierno autoritario trasciende, se profundiza y consolida, recurriendo a mecanismos "democráticos" (formales, no sustanciales) mientras convive y "gestiona" simultáneamente escenarios de conflicto letal, tales como guerras civiles, de guerrillas, entre otros (el caso paradigmático sería precisamente Colombia) (ver PUELLOSOCARRÁS; PUELLO-SOCARRÁS, 2017). 
MIROWSKI, 2013, p. 87). Esta caracterización es perfectamente aplicable para el caso de la Gobernanza: la forma de gobierno emergente en la etapa del capitalismo neoliberal para el nuevo milenio.

Más allá de sus variantes específicas y considerando sus dimensiones formales (jurídicas y legales), concretas (organizacionales) y materiales (sus efectos sobre las relaciones sociales, ampliamente consideradas), la combinación Gobernanza \& Nueva Gestión Pública ha significado, entre otras cosas:

1) La creciente empresarialización y casi ilimitada mercantilización de los espacios, esferas y dimensiones de la vida social. La introducción de lógicas de mercado y cuasi-mercados a través del relativo abandono (y menor vigencia) de la intervención o planificación estatales, consagrando la acción del Estado neoliberal en torno a dos modalidades: a) la des-regulación; y, más recientemente, b) la regulación ${ }^{9}$.

Los primeros enfoques formulados para acceder a las reformas estatales en la primera fase de la era neoliberal, directamente desreguladores ("Reinventar el gobierno", ver OSBOURNE; GAEBLER, 1992; OSBOURNE; PLASTRICK, 2006), fueron poco a poco perdiendo vigencia, y por mediación de nociones más ajustadas y funcionales como el "Estado modesto" (CROZIER, 1992), es decir: regulador, y el Post-burocratismo (BARZELAY; ARMAJANI, 1998), se abrió paso a la construcción parsimoniosa pero sostenida del Estado emprendedor (MAZZUCATO, 2014), fase superior del Estado neoliberal y síntesis de la gobernanza del sector público: la gobernanza emprendedora de la nueva gestión pública (ver LANE, 2000, p. 3) ${ }^{10}$.

Durante el nuevo milenio estas orientaciones que han respaldado, técnica, política e ideológicamente las relaciones contemporáneas entre el Estado y la Sociedad, suscitando

\footnotetext{
${ }^{9}$ Conceptualmente hablando, deben distinguirse cuatro (4) formas paradigmáticas de acción estatal. Fueron selectivamente desplegadas a lo largo de los siglos XX y XXI y se sintonizan con fases históricas específicas de los regímenes político-económicos estatales: (1) Desregulación (Neo/Liberalismo ortodoxo); (2) Regulación ('Nuevo' neoliberalismo heterodoxo); (3) Intervención (Keynesiana); (4) Planificación centralizada (Socialismos "reales"). Debe subrayarse que (1) y (2) son ejemplos típicos de la Planeación Descentralizada. Esta categorización se alimenta de las discusiones sostenidas por Jan Tinbergen (1964) y Charles Bettelheim (1965).

${ }^{10}$ Aunque el llamado de Standing (2018) para revivir una fase de "re-inserción" y nuevas regulaciones, alusión basada en una asunción acrítica de Polanyi, en nuestra opinión resulta problemática, su diagnóstico sobre este particular es acertado: "Contrariamente a lo que se afirma de modo generalizado, no ha habido ninguna desregulación del mercado, sino más bien una re-regulación del Estado. Así, por ejemplo, la autorregulación de las ocupaciones profesionales (en buena medida ignorada por los economistas convencionales del trabajo) se ha visto desplazado por la regulación estatal por medio de complejos sistemas de concesión, mientras que el mercado de trabajo y la política social se han ido desplazando hacia la evaluación condicionada a los medios económicos o el comportamiento y hacia programas de trabajo para desempleados... Toda apariencia de política social universalista asentada en derechos se ha ido batiendo en retirada en casi todas partes" [énfasis propio].
}

REAd | Porto Alegre - Vol. 24 - No 2 - Maio / Agosto 2018 - p. 31-49 
nuevos esquemas de gobierno y la reorganización institucional intra y extraestatal, se tornan una realidad palpable (PUELLO-SOCARRÁS, 2018b).

Antes que adecuaciones exclusivamente "técnicas", tal y como se quisieron presentar, este tipo de contra-reformas vienen significando una reconfiguración eminentemente política de profundos impactos al nivel de las sociedades (ver OXFAM, 2016, 2017 y 2018).

2) El trance hacia el EST de la Gobernanza \& la NPM, registra dos tendencias convergentes: 2.1) la deconstrucción/destrucción paulatina de los (ahora considerados "caducos") derechos del bienestar; y, complementariamente, siguiendo la necesaria articulación global con el caso latinoamericano, 2.2) la preservación gradual -en tiempos, lugares e intensidades- de las situaciones sociopolíticas y económicas producidas por la condición autoritaria. Más puntualmente: la anulación/suspensión de los derechos humanos, concebidos comprensivamente como libertades civiles, políticas y, especialmente, sociales y culturales.

Una de las consecuencias de lo anterior tiene que ver con la paulatina disolución de los antiguos complejos sistemas de Políticas públicas de mediados del siglo XX, anteriormente funcionales a la estabilización legitimada de la acumulación de capital mediante la promoción de los servicios públicos estatales orientados a derechos (especialmente, sociales). A la inversa, el Estado neoliberal en el siglo XXI activa la gestión de simples medidas públicas (por lo general, incompetentes, incoherentes e incompletas) cuando se trata de "regular" las problemáticas en las zonas sociales medias y, especialmente, bajas. Una situación que, en términos de la acción estatal, marca un contraste cada vez más pronunciado pues los aparatos de Estado a la hora de activar su brazo punitivo se tornan abiertamente eficientes, eficaces y competentes ${ }^{11}$.

La segmentación formal y la obstrucción material de los derechos en general son el resultado de esta convergencia.

El Estado neoliberal comprensivo licúa entonces las nociones: "fuerte” de ciudadanía del EKB y “débil” del EBA, instalando la versión más funcional de cliente (últimamente, matizada en los "ciudadanos-clientes") para reforzar estratégicamente la despolitización basada en el individualismo extremo. El "contrato" (empezando por el contrato "de gestión")

\footnotetext{
${ }^{11}$ En esto radica la debilidad de las hipótesis sobre la "ausencia estatal" ó la "falta de voluntad gubernamental", las cuales interpretan en ello déficits (técnicos o políticos) del Estado en la era neoliberal. Se equivocan al no contemplar que la no-decisión (ver BACHRACH; BARATZ, 1962) es la contracara -a la vez excluyente y complementaria- en la toma de decisiones institucionales del tipo de acción reguladora típica de esta forma estatal. De hecho, tomando en cuenta la dimensión de las no-decisiones se evidencia que allí donde se interpreta "ausencia del Estado" habría todo lo contrario: "presencia"; y, donde se diagnostica "falta de voluntad", se evidencia "voluntad firme".
} 
se eleva como la mediación fundamental del actual relacionamiento social, incluyendo aquel materializados en los aparatos de estado, y su funcionamiento estructural.

Las emergentes esferas públicas-no-estatales y el dominio público-privado, donde se promociona como protagonista la llamada Sociedad Civil (stricto sensu, el mundo organizado de la sociedad económica) y se ensalza como valor la co-operación, avanzan en detrimento de lo público estatal ${ }^{12}$. Así, no sólo se logra actualizar la (vieja) semántica de las responsabilidades políticas de la institucionalidad estatal anterior que respaldaba el pacto social: demandas, reivindicaciones y conflictividades colectivas. Además, se protege con esta recodificación que la precarización y los problemas de aglutinación (y cohesión), puntualmente: la desintegración social, exacerbados por las crecientes contradicciones en esta nueva fase del capitalismo de mercado, sean internalizados (individualizados) y puestos entre paréntesis (disueltos como problemáticas socialmente relevantes) ${ }^{13}$.

En distintos balances, gobernanza y nueva gestión pública no son solamente dos dispositivos que explicarían la clausura y no progresividad de los derechos (al menos, bajo la semántica que alcanzaron durante el siglo XX); aquello que, entre otros, Wacquant (2009) denomina la "retracción del Estado de Bienestar" -allí donde efectivamente existió-.

De la mano de sus resultados e impactos concretos, ambos son cruciales para 'gestionar el gobierno' de la inseguridad social provocada, a través de la combinación de esquemas simples de medidas públicas (limitados, segmentados, inactivos y siempre actuando en el 'límite'; v.gr. pobreza y desigualdad extremas) y aparatos punitivos complejos (expansivos, intrusivos y proactivos) en las regiones "más bajas del espacio social" (WACQUANT, 2009, p. 431). La intensificación del consenso de la fuerza y la normalización de las expresiones autoritarias como fuente no excepcional de la legitimidad son elementos arquitectónicos dentro de la fase actual.

\footnotetext{
${ }^{12}$ Aunque poco se señala, esto también significa la destrucción de otros tipos de espacios, dominios, esferas. En particular y, sobre todo, obstruye acciones políticas y solidaridades alternativas, especialmente de naturaleza comunal. Por lo tanto, hay que distinguir entre, por un lado, la co-operación bajo la semántica corporativa y la lógica de los cuasi-mercados y en tanto sustituto imperfecto de la competencia (sistema de precios) (ver COASE, 1994, p. 33-49) y, por otro lado, la cooperación bajo el sentido de las solidaridades, por ejemplo, sociales, comunales, etc. La primera acepción es reiterada por las teorías y modelos de la gobernanza, desde las primeras formulaciones contemporáneas hechas por R. Coase.

13 “[...] es desde esta racionalidad política que el Estado desarrolla nuevos modelos de gobernanza que buscan crear un 'régimen de Verdad' que es necesario para lograr lealtad y consenso. De esta manera, el Estado busca reconstruir la base de su legitimación a través de la relocalización, y desde luego la despolitización del poder estatal de los individuos y los grupos. El neoliberalismo con su énfasis en el "emprendedor de sí mismo" (enterprising-self); llega a convertirse en un mecanismo clave para el proceso de despolitización". [énfasis propio] (BONAL, 2003. p. 9).
}

REAd | Porto Alegre - Vol. 24 - No 2 - Maio / Agosto 2018 - p. 31-49 
En Colombia, donde la organización institucional del régimen político contemporáneo recrea estas tendencias: el enfoque de la gobernanza ${ }^{14}$; la conducción operativa de los aparatos estatales reproducen el esquema de la Nueva Gestión Pública "orientada a resultados" (DNP, 1995); y los formatos de "cadena de valor" ${ }^{15}$ como guía para la generación de acciones públicas (DNP, 2015), es necesario interrogarse si la construcción de la Paz y las expectativas respecto a su materialización social, precisarían o no, de una transición básica en el sistema estatal-administrativo hoy existente, convocando uno renovado y diferente; amplio y complejo para asumir los desafíos que representaría este reto histórico, a todas luces, inédito.

\section{5 ¿GOBERNANZA Y NUEVA GESTIÓN PÚBLICA PARA LA PAZ?}

Más allá de los debates teóricos disponibles o las evaluaciones empíricas que gran parte de la literatura especializada viene ofreciendo recientemente sobre el tema, y que visibilizan un consenso claramente desfavorable al desempeño global de las oleadas de reforma pro-nueva gestión pública ${ }^{16}$, y justamente como lo plantean Dunleavy et al. (2006, p. 468): "han conducido a desastres en términos de políticas", la respuesta a la interrogante sobre la conveniencia o no, de adelantar una transición durante la etapa de pos-acuerdos en Colombia, estaría en principio fuera de toda discusión y anticipada, simplemente recurriendo al sentido común.

Realizar cambios y transformaciones en la estructura del Estado, en las lógicas que definen el funcionamiento de sus aparatos y en la generación de acciones institucionales,

\footnotetext{
14 "El actual esquema de gobernanza de Colombia se basa en la total separación de los tres poderes del Estado, un compromiso con una economía de libre mercado, y el papel de liderazgo que juega el poder Ejecutivo en la articulación e implementación de reformas para mejorar la capacidad de respuesta del gobierno a las necesidades de los ciudadanos" [énfasis propio] (OCDE, 2015, p. 64).

15 "La cadena de valor es la relacion secuencial y logica entre insumos, actividades, productos y resultados en la que se anade valor a lo largo del proceso de transformacion total. Se puede decir que en una primera etapa de la cadena de valor se toman insumos, que tienen unos costos asociados, y bajo alguna tecnología y procesos (llamados actividades), se transforman en productos (bienes y servicios). Luego, en una segunda etapa, los productos, bajo condiciones específicas, generan resultados que deben cumplir parcial o totalmente los objetivos formulados" (DNP, 2017, p. 5).

${ }^{16}$ En el caso de las experiencias de NPM, se estiman toda clase de problemas (Christensen \& Lægreid, 2007; Van Gestel \& Teelken, 2004). Dunleavy et alt. (2006) no han dudado de calificar este periodo como "desastroso" en términos de políticas, asegurando "la muerte de la nueva gestión pública". Sin que, en nuestra opinión, sean auténticas alternativas superadoras -de hecho, parecerían ser "críticas" bastante funcionales, sin capacidad para generar nuevos paradigmas epistémicos ni rupturas concretas del status quo neoliberal al reforzar la lógica de la gobernanza (ver DAHL; SOSS, 2014), resultan sintomáticas las continuas reiteraciones a la "Post-nueva Gestión Pública" (ver CHICA; SALAZAR, 2016) y el Valor Público (MOORE, 1997; BOZEMAN, 2007).
} 
tanto a nivel legal como organizacional, con las implicaciones que esto representaría al nivel de las relaciones societales, sería el presupuesto por antonomasia para desatar la fase de implementación de los Acuerdos y el insumo primordial para el inicio del proceso de construcción de la Paz.

Para transitar desde una 'condición de Guerra' indeseada en retrospectiva hacia una 'situación de Paz' en construcción - deseada pero incierta en prospectiva - se requieren sostener cambios cuantitativos y cualitativos robustos en las dinámicas y lógicas estatales antes vigentes. Incluso, se trata de revertir las dinámicas. Por un lado, desactivando las expresiones de la condición autoritaria heredada, hoy vigente, recapacitando la actual gobernanza gestionaría del Estado y, simultáneamente, por otro lado, activando la reconstrucción estatal, vía la instauración institucional de los sistemas de políticas públicas orientadas a los derechos humanos, en sentido amplio y en todas sus dimensiones civiles, políticas, sociales, culturales, hoy por hoy residual.

El propósito de la transición sería necesariamente sentar las nuevas bases para tramitar las contradicciones y la conflictividad sociales, y sus expresiones asociadas, entre ellas: la armada, tanto estatal y paraestatal como insurgente (ver CHCV, 2015), en torno a una ‘institucionalidad pos-acuerdo’ (PUELLO-SOCARRÁS; PUELLO-SOCARRÁS, 2016).

Es una verdad Perogrullo que la arquitectura estatal constituida para la guerra no puede persistir bajo un armazón idéntico para alcanzar una Paz estable y duradera. Sería no sólo ilógico sino también poco sano - mentalmente hablando (insane), pues el tema convoca ya responsabilidades en relación con la vida en general y la humana, social, incluso, natural en particular -, esperar un resultado distinto si las cosas se continúan haciendo de la misma forma, trayendo a colación la frase del epígrafe de autoría de Rita Mae Brown.

Al respecto, el Acuerdo Final fue un diseño modesto que no introdujo demasiada complejidad para facilitar la transición hacia la construcción de la Paz. Antes bien, relajó las precondiciones para el cabal cumplimiento de lo pactado por parte del Estado colombiano. A diferencia de otras experiencias, orientadas por pactos maximalistas donde se negociaron cambios (relativamente) estructurales - al menos, formalmente y en la letra -, en el caso colombiano, bajo una óptica claramente minimalista, se acordaron "reformas y ajustes institucionales" mínimos que permitieran "atender los retos que la paz demande, poniendo en marcha un nuevo marco de convivencia política y social” (AF, 2016, p. 7). A lo largo del texto, se insiste en ello, refiriéndose a varios asuntos en particular (AF, 2016: 17, 37, 42, 44, $49,52,53,73,89,92,97,108,119,121,122,181,185,190$ у 196). 
Si se analiza con cuidadosa rigurosidad el contenido de lo pactado -más allá de los detalles inéditos que, por obvias razones, se inscriben dentro de la singularidad histórica fruto de las negociaciones entre las antiguas FARC-EP y el gobierno colombiano- sería justo interpretar que el AF no implica otra cosa que cumplir con las promesas incumplidas de la Constitución política hoy vigente. Más puntualmente: la expectativa de materializar el Estado Social de Derecho, deuda histórica aún por cristalizar.

No obstante, partiendo de lo antes registrado durante el proceso de implementación temprana y lo que se pronostica hoy para la fase tardía, a partir del diagnóstico realizado sobre el Plan Marco de Implementación, las reformas institucionales son casi inexistentes y los ajustes institucionales tímidos ${ }^{17}$. El análisis en general y en particular del proceso de diseño del PMI no refleja siquiera mínimamente lo pactado.

Insistiendo que se trata de un Acuerdo de Paz minimalista, habría que advertir que las posibles desviaciones (distorsiones, desconocimientos, simulaciones) -por pequeñas que sean- lógicamente introducirían un nivel de incertidumbre apreciable en el presente y un grado significativo de volatilidad hacia el futuro, a los procesos de implementación y construcción de la Paz, considerado integralmente.

\section{REFERENCIAS}

\section{BACHRACH, P., BARATZ, M. Two faces of power. The American Political Science}

Review, v. 56, n. 4, p. 947-952, 1962.

\footnotetext{
17 El debate sobre la (des)financiación del PMI, tal y como se consigna en las "Salvedades - FARC", es paradigmático e ilustrativo. En términos de la discusión sobre el orden presupuestal de la paz y la guerra, David Cortright, actual director del programa Barómetro del Kroc Institute for International Peace Studies, institución que apoya "técnicamente" el seguimiento a la implementación por mandato del AF, aun siguiendo enfoques de gobernanza y a partir de análisis convencionales, alerta sobre las denominadas "situaciones de posconflicto", lo siguiente: "El presupuesto militar elevado es parte del problema en las situaciones de post-conflicto, no parte de la solución. En lo substancial, lo hace más propenso al conflicto. Los Estados que priorizan los gastos militares en vísperas de un acuerdo de paz están apostando, incluso inadvertida o intencionalmente mostrando una voluntad de incumplir los acuerdos negociados. Priorizar los programas sociales tales como educación y salud, de otra parte, podría mostrar una intención de concentrarse en el desarrollo de la paz y el crecimiento económico en lugar de más conflictos armados. La importancia del gasto social aparece constantemente en las investigaciones sobre la relación entre gobernanza y paz" [énfasis propio] (CORTRIGHT et al., 2013, p. 10). En contraste con los recursos asignados al Plan Marco, el presupuesto militar del Estado aumenta. Esta situación, se corrobora a través de un análisis en materia presupuestal para el año 2018 y que se puede resumir como: "MinDefensa, el que más ganó en el presupuesto 2018... Inclusión social, sector que más perdió" "énfasis propio] (EL TIEMPO, 2017). Otros temas, como la reincorporación temprana son abiertamente gravosos. Y, no sólo por sus posibles implicaciones sociopolíticas sino en sentido elementalmente humanitario frente a la población de los Espacios Territoriales de Capacitación y Reincorporación, en materia de salubridad, salud, etc.
} 
BARZELAY, M., ARAMAJANI, B. Atravesando la burocracia: una nueva perspectiva de la administración pública. México: FCE, 1998.

BETTLEHEIM, C. Planeación y crecimiento acelerado. México: FCE, 1965.

BONAL, X. The neoliberal educational agenda and the legitimation of crisis: old and new state strategies. British Journal of Sociology of Education, v. 24, n. 2, p. 159-175, 2003. BOZEMAN, B. Public values and public interest: counterbalancing economic individualism. Washington: Georgetown University Press, 2007.

MOORE. M. Creating public value: strategic management in government. Harvard: Harvard University Press, 1997.

CABRERO, E. 1998. Estudio introductorio: gestión pública, ¿la administración pública de siempre bajo un nuevo disfraz?. In: BOZEMAN, B. (Ed.). La gestión pública: su situación actual. México: FCE, 1998, p. 19-36.

CENTRO LATINOAMERICANO DE ADMINISTRACIÓN PARA EL DESARROLLO.

CLAD. Una Nueva Gestión Pública para América Latina. Documento doctrinario suscrito por el Consejo Directivo del CLAD, 1998.

CHICA, S., SALAZAR, C. Nueva y posnueva gestión pública ¿Continuidad o ruptura de las doctrinas de reforma a partir de 1990? Administración y Desarrollo, v. 46, n. 1, p.100-125, 2016.

COASE, R. La empresa, el mercado y la ley. Alianza: Madrid, 1994.

COMISIÓN HISTÓRICA DEL CONFLICTO Y SUS VÍCTIMAS. CHCV. Contribución al entendimiento del conflicto armado en Colombia. Bogotá: Imprenta Nacional, 2015.

COLTRIGHT, D., SEYLE, C., WALL, K. Governance, democracy and the peace: how state capacity and regime type influence the prospects for war and peace. Broomfield: One Earth Future Foundation, 2013.

CROZIER, M. Estado modesto, Estado moderno: estrategia para el cambio. México: FCE, 1992.

CROZIER, M., HUNTINGTON, S., WATANUKI, J. The crisis of democracy: report on the governability of democracies to the Trilateral Commission. New York: New York University Press, 1975

CHRISTENSEN, T. LÆGREID, P. Reformas Post nueva gestión pública. tendencias empíricas y retos académicos. Gestión y Política Pública, v. XVI, n. 2, p. 539-564, 2007. DAHL, A.; SOSS, J. Neoliberalism for the common good? Public value governance and the downsizing of democracy. Public Administration Review, v. 74, n.4, p. 496-504, 2014. 
DEPARTAMENTO NACIONAL DE PLANEACIÓN. DNP. Gestión Pública orientada a resultados. Documento CONPES 2790 (21 de junio), 1995.

DEPARTAMENTO NACIONAL DE PLANEACIÓN. DNP. Guía para la construcción y estandarización de la Cadena de Valor. Bogotá: DNP - Dirección de Inversiones y Finanzas Públicas. Versión 5.0 (enero), 2017.

DUNLEAVY, P., MARGETTS, H., BASTOW, S., TINKLER, J. New public management is dead: long live digital-era governance. Journal of Public Administration Research and Theory n.16, p. 467-494, 2006.

EAGLETON-PIERCE, M. Neoliberalism: key concepts. New York: Routledge, 2016. ECHEBARRÍA, K.; CORTÁZAR, J. Las reformas de la administración y el empleo públicos en América Latina. In: LORA, E. (Ed.) El estado de las reformas del Estado en América Latina. Washington: Banco Inter-americano de Desarrollo, 2007.

EL TIEMPO. Ministerio de Defensa el que más ganó en el presupuesto 2018 ( 28 de julio). JESSOP, B. 2008 ¿Narrando el futuro de la economía nacional y el Estado nacional? Puntos a considerar acerca del replanteo de la regulación y la re-invención de la gobernancia.

Documentos y Aportes en Administración Pública y Gestión Estatal, v. 6, n. 7, p. 7-44 2008 .

JESSOP, B. Crisis del Estado de Bienestar: hacia una nueva teoría del Estado y sus consecuencias sociales. Bogotá: Siglo del Hombre, 1999.

GUERRERO, O. La nueva gerencia pública: neoliberalismo en administración pública. México: Fontamara, 2004.

LANE, J. 2New Public Management. London: Routledge, 2000.

MARINI, R. M. Subdesenvolvimento e revolução. Florianópolis: Insular, 2013.

MAZZUCATO, M. EI Estado empreendedor: mitos del sector público frente al sector privado. Barcelona: RBA, 2014.

MESA DE CONVERSACIONES. Acuerdo Final para la terminación del conflicto: la construcción de una paz estable y duradera. Bogotá: Torreblanca (incluye folleto: Nuevo Acuerdo Final), 2017a.

MESA DE CONVERSACIONES. Nuevo Acuerdo Final para la terminación del conflicto: la construcción de una paz estable y duradera. Notas sobre los cambios, ajustes y precisiones... Bogotá: Torreblanca (incluye folleto:), $2017 \mathrm{~b}$.

MIROWSKI, P. Nunca dejes que una crisis te gane la partida: ¿Cómo ha conseguido el neoliberalismo, responsable de la crisis, salir indemne de la misma? Barcelona: Planeta, 2013.

REAd | Porto Alegre - Vol. 24 - No 2 - Maio / Agosto 2018 - p. 31-49 
MOORE, M. Creating public value: strategic management in government. Cambridge: Harvard University Press, 1997.

ORGANIZACIÓN PARA LA COOPERACIÓN Y EL DESARROLLO ECONÓMICOS. OCDE. Colombia: la implementación del buen gobierno. OECD Publishing, 2014. ORGANIZACIÓN PARA LA COOPERACIÓN Y EL DESARROLLO ECONÓMICOS. OCDE. Governance in transition: Public Management reforms in OECD countries. Washginton: OECD Publications and Information Center, 1995.

O’DONNELL, G. El Estado Burocrático-Autoritario: triunfos, derrotas y crisis. Buenos Aires: Editorial Belgran, 1982.

O’DONNELL, G. Contrapuntos: ensayos escogidos sobre autoritarismo y democratización. Buenos Aires: Paidós, 1992.

OSBOURNE, D., GAEBLER, T. La reinvención del gobierno: la influencia del espíritu empresarial en el sector público. Barcelona: Paidós, 1992.

OSBOURNE, D., PLASTRICK, P. Herramientas para transformar el gobierno. Barcelona: Paidós, 2006.

OXFAM. Una economía al servicio del 1\%: acabar con los privilegios y la concentración de poder para frenar la desigualdad extrema. Oxford: Oxfam International, 2016.

OXFAM. Una economía para el 99\%: es hora de construir una economía más humana y justa al servicio de las personas. Oxford: Oxfam International, 2017.

OXFAM. Premiar el trabajo, no la riqueza: para poner fin a la crisis de desigualdad, debemos construir una economía para los trabajadores, no para los ricos y poderosos. Oxford: Oxfam International, 2018.

PUELLO-SOCARRÁS, J. F. Nueva gramática del neo-liberalismo: itinerarios teóricos, trayectorias intelectuales, claves ideológicas. Bogotá: Universidad Nacional de ColombiaUNIJUS, 2008.

PUELLO-SOCARRÁS, J. F. Pacta sunt servanda y el no cumplimiento del acuerdo final por parte del Instituto Kroc. Revista Izquierda, n. 72, p. 57-61, 2017.

PUELLO-SOCARRÁS, J. F. ¿Heteronomía relativa? Esbozos en torno a la inversión de la "lógica" en las políticas públicas en la era del Capitalismo neoliberal (en edición), 2018a.. PUELLO-SOCARRÁS, J. F. Nuevo neo-liberalismo y administración pública. reinvención gubernamental, post-burocracia y nueva gestión pública. Vademecúm de la Administración Pública (en edición) 2018b.

PUELLO-SOCARRÁS, G. E. ; PUELLO-SOCARRÁS, J. F. ¿La época de los 'post'? Conflicto social-armado, acuerdo de paz y anocracia neoliberal en Colombia. In: VIDAL DE 
LA ROSA, G. (Ed.). Política Latinoamericana Contemporánea. México: Universidad Autónoma Metropolitana: 2017, p. 305-346.

RAMIÓ MATAS, C. Los problemas de la implantación de la nueva gestión pública en las administraciones públicas latinas: modelo de Estado y cultura institucional. Revista Reforma y Democracia, n. 21, p. 1-24, 2001.

ROUQUIÉ, A. A la sombra de las dictaduras: la democracia en América Latina. Buenos Aires: FCE, 2011.

SERNA DE LA GARZA, J. M. Globalización y gobernanza. México: UNAM, 2010.

SOLÍS, J. L. El Estado como categoría de la crítica marxista de la economía política: el debate sobre la “derivación”. In: ARTOUS, A. et al. (Orgs.). Naturaleza y forma del Estado capitalista. Buenos Aires: Herramienta, 2016, p. 99-129.

STANDING, G. El precariado bajo el capitalismo rentista. 2018. Disponible en:

http://www.sinpermiso.info/textos/el-precariado-bajo-el-capitalismo-rentista. Acceso en: 24 Jun. 2018.

TINBERGEN, J. Central planning. New Haven; London: Yale University Press, 1964.

VAN GESTEL, N. TEELKEN, C. Servicios de educación superior y de seguridad social en los Países Bajos. Institucionalismo y Nueva gestión política. Gestión y Política Pública, v. XIII, n. 2, p. 427-467, 2004.

VILLAMIZAR, D. Las guerrillas en Colombia: una historia desde los orígenes hasta los confines. Bogotá: Debate, 2017.

WACQUANT, L. Castigar a los pobres: el gobierno neoliberal de la inseguridad social. Barcelona: Gedisa, 2009. 